constructions automatically raises questions about the actual spaces to which these fantasies are attached. The spatial boundedness of elite education allows for a reconsideration of the fairly un-pastoral facets that the aesthetics of the picturesque tends to veil, even though and because they shape and define the elite educational space: class and capital. Keeping these two guiding assumptions in mind, I now want to turn to the three categories that are at the heart of my exploration of the discourse of elite education-eliteness, merit, and class-and introduce each of them in detail.

\title{
3. 'Very Important, Very Powerful, or Very Prominent': Eliteness in America
}

In Beyond the Ruling Class: Strategic Elites in Modern Society (1963), sociologist Suzanne Keller writes about the inevitability of elite influence: "The existence and persistence of influential minorities is one of the constant characteristics of organized social life. Whether a community is small or large, rich or poor, simple or complex, it always sets some of its members apart as very important, very powerful, or very prominent" (3). While few scholars would dispute this, academic inquiry into the composition and distribution of power remains replete with terminological confusion and conceptual obscurity. Reflecting on the complexity of the possible structural distinctions, Anthony Giddens points out:

We should be able to recognize [...] that there can exist a 'governing class' without it necessarily being a 'ruling class'; that there can exist a 'power elite' without it necessarily being either a 'ruling' or a 'governing class', that there can be a system of 'leadership groups' which constitutes neither power 'elite', nor governing class' or 'ruling class'; that all of these social formations are compatible with the existence of an 'upper class'; and finally, that none of these categories prejudices the question of the relative primacy of the 'political' and 'economic' spheres within the class structure. (3)

Fraught with a variety of terminological and theoretical complications, the conceptual terrain of eliteness is far from easy to navigate. As the terms discussed by Giddens suggest, stratification in contemporary Western societies like the United States occurs simultaneously along several different dimensions-economic, social, political, and cultural, among others-and every 
critical interrogation of eliteness has to decide which of these hierarchies to emphasize, and which conceptual frameworks to apply.

My research interests are located in the realm of culture, discourse, aesthetics, and narrative-the stories that we tell ourselves to explain why things are the way they are, the myths that encourage us to dream of better futures, the ideas that are sold to us with the promise of change and mobility; but also, in turn, the critical or potentially subversive narratives and artifacts that challenge or undermine the status quo. Since this book thus interrogates the epistemological structures and practices surrounding the elite educational space, I do not use the term 'elite' as a precise sociological category; that is, my primary concern is not to determine or discuss who does or does not belong to the American elite(s), whatever its exact conceptualization may be. Instead, I am interested in the cultural negotiation of elite distinction, in the aesthetic and discursive practices and patterns surrounding those educational institutions and their members, who are deemed or deem themselves "very important, very powerful, or very prominent," as Keller puts it (3). Thus, I use the term 'elite(ness)' and the concept of elite distinction as a signifier of a number of related ascriptions I discuss in more detail below. In addition, I ask how the materials themselves use the term or related terms, and to what effect.

\section{A Cultural Studies Understanding of Eliteness}

The term 'elite' entered the English language by way of the French verb elire, which, in turn, derives from the Latin verb eligere: to choose. Whenever we speak of an elite, then, we speak of an individual or a group that was chosen-presumably by someone, presumably on the grounds of something, presumably for some kind of purpose. At the same time, the term 'elite' always implicitly includes reference to 'the masses'-the great number of people who have not been chosen and thus do not belong. The concept becomes meaningful only through the implied exclusion of its opposite; there can be no 'fortunate few' without the 'unfortunate many'. An elite community consequently needs gatekeepers who decide on whom to admit and whom to exclude, and on what grounds-a position that is particularly important in the context of education.

The history of the usage of 'elite' reflects its semantic versatility. Emerging in eighteenth-century France, the term was first used by the aspiring bourgeoisie as a democratic battle cry against the nobility and the clergy, signifying the preference for individual achievement rather than lineage and familial 
connections as criteria to decide on who ought to fill society's top positions (Hartmann 2007: 9). Toward the end of the nineteenth century, however, the term's meanings began to change profoundly. The dramatic growth of the population across Europe and the United States brought with it urbanization and the emergence of an increasingly self-conscious working class, developments that seemed to threaten the position of the bourgeoisie and gave rise to various strands of pseudo-scientific and elitist thought. Informed, among other things, by Gustave Le Bon's highly influential The Crowd: A Study of the Popular Mind (1895), the meaning of eliteness then shifted from a qualitative to a quantitative conceptual framework, from signifying non-hereditary qualifications to being posited as the opposite of 'the masses'.

It is in this context that the first three classic elite theories were formulated by political scientist Gaetano Mosca (The Ruling Class, 1896), economist and sociologist Vilfredo Pareto (The Mind and Society: A Treatise on General Sociology, 1916), and sociologist Robert Michels (Political Parties: A Sociological Study of the Oligarchic Tendencies of Modern Democracy, 1911). By the middle of the twentieth century, the concept of elite distinction, along with the term 'elite', had become discredited due to its affinity with and utilization by fascist thought. Michels, for instance, had joined Benito Mussolini's Fascist Party in 1926. Beginning in the 1970s, the concept was slowly reformulated and ultimately reintroduced to critical (sociological) scholarship and public discourse. In Germany, this reformulation consisted primarily of adding qualifying prefixes that were meant to stress performance-based aspects or a certain sense of moral obligation-Leistungselite, Wertelite, and, more recently, Verantwortungselite-while in the United States pluralist and functionalist conceptions of elite influence gained currency. These developments and semantic modulations suggest the enduring appeal of the concept of eliteness, an attractiveness that prompts recurring attempts at updating the concept and endowing it with new legitimacy.

As is the case with many concepts that circulate both in academic and in popular discourse, the term elite is often used without any explicit definition or distinction from other, related terms. Examples of this tendency can be found, for instance, in Ross Douthat's Privilege (2005), which I discuss in greater detail in Chapter 2. Published under the label 'Sociology' by Hyperion Books, it was written by a journalist with no sociological training, and could be described more adequately as a mixture of autobiography, cultural critique, and political commentary, relying heavily on anecdotal evidence and personal experience. Douthat uses terms such as "modern elite" (11), "rul- 
ing class" (63), and "privileged class" (12) synonymously and without offering definitions for any of them. He does not venture to distinguish between the different axes of stratification: economic, political, or cultural. Douthat's usage is symptomatic of the manner in which eliteness is talked about, and it demonstrates the concept's discursive advantages and pitfalls: Convenient in its vagueness, it encompasses a diffuse conglomerate of socio-economic, cultural, and ideological factors, and often obscures rather than illuminates the specifics of these different dimensions.

I chose eliteness as one of the key concepts for this study for a number of reasons. First, compared to the other terms discussed by Giddens above, 'elite' is neither as straightforwardly economic as 'upper class' nor as explicitly political as 'ruling class' or 'governing class'. It thus calls for a more open and inclusive conversation about economic and political dynamics, while also allowing the inclusion of cultural factors. Second, despite its semantic instability, the term can be used quite productively within cultural studies. Eliciting ambivalent, if not downright divisive responses, the notion of eliteness refers to fantasies, fictions, and ideologies rather than any kind of actual, quantifiable 'reality'. This does not mean that the realities inevitably underlying such fictions are not my concern, but my analysis is primarily interested in the cultural imagination. Third, an investigation of eliteness seems to be particularly fitting in the American context, as the concept does allude to some form of meritoriousness. Distinction, the term 'elite' implies, is conferred upon those who deserve it on the grounds of their actions and achievements. The affinity between the concept of elite distinction and grand narratives of capitalism and neoliberalism-often told in the ideological framework of the meritocracy-is written into the term itself.

At the same time, the prevalence of anti-elitist sentiment in the United States complicates this picture in interesting ways. In this context, the distinction between different types of eliteness-financial, social, intellectual, among others-becomes particularly important. Some of these types seem to be more compatible with core motifs in American culture than others, so that extreme wealth, for instance, is often seen as less offensive than extreme intellectualism. Political bias plays a crucial role in these dynamics, so that both anti-elitism and the celebration of eliteness take different forms in Republican and Democratic circles-Mitt Romney's wealth and Barack Obama's ties to prestigious educational institutions, for example, were alternately criticized and praised during the 2012 presidential campaign. 
Despite its elusiveness and contradictory history, a closer look at the usage of the term 'elite' suggests that there is indeed a kind of master narrative in the discourse of elite distinction as to what the concept of eliteness signifies. Thus, in my understanding, the concept has three comparatively stable connotations: First, it signifies exclusivity and a process of selection; second, it alludes to excellence and exceptionalism; and third, it connotes power and influence, be it social, political, or economic. Not all materials that constitute my corpus use the term 'elite' itself, but all of them draw on related concepts that carry roughly the same three connotations. The most prominent of these related terms, in the educational context, are 'exclusive', 'selective', 'prestigious', 'distinguished', 'competitive', 'privileged', and 'affluent'. In addition, fictional and non-fictional texts alike use the proper names of existing elite institutions for similar semantic purposes. Like the concept of eliteness itself, these terms revolve around the sometimes contradictory, sometimes complementary issues of money, talent, and power.

\section{Education in the American Imagination}

Throughout history, higher education has held an ambivalent position in the American cultural imagination. Colleges and universities have been met with skepticism and praise alike, celebrated for their emancipatory and equalizing potentials and dismissed as unnecessary, snobbish, or out of touch with the 'real world'. The Puritans cherished education as spiritual aid and means to implement their religious mission, and consequently invested time and money in the establishment of educational infrastructures. ${ }^{2}$ As the nation grew, however, and in particular in the nineteenth century, voices critical or dismissive of formal education emerged. Countless stories of education gained beyond the confines of educational institutions exist, most famously perhaps that of Melville's Ishmael, who proclaims in Moby Dick (1851) that "a whale-ship was my Yale College and my Harvard" (122). Echoing this type of sentiment, writer and philosopher Elbert Hubbard, for instance, wrote in an 1899 essay: "It is not book-learning young men need, nor instruction about this or that, but a stiffening of the vertebrae which will cause them to be loyal to a trust, to act promptly, concentrate their energies: do the thing" (quoted in

2 For more information on the Puritan view of education, consider John Morgan's Godly Learning: Puritan Attitudes towards Reason, Learning and Education, 1560-1640 (Cambridge UP, 1988). 
Lemann 51). This principled dismissal of formal education can be traced well into the twentieth and twenty-first centuries. Lemann points out that many of the "celebrity representatives of the possibility of success for the common man" (50)-Andrew Carnegie, Edward Bok, and Benjamin Franklin, among others-had very little formal education and started to work early in their lives. The prominent figure of the so-called self-made man, populating for example the stories of Horatio Alger, did not succeed by means of education but through luck and/or hard work. This 'worldly' paradigm of dismissing formal education is complemented (and, to an extent, complicated) in contemporary discourse by recent stories of Bill Gates or Mark Zuckerberg, both elite college dropouts turned business tycoons.

Anti-intellectualism - what Richard Hofstadter in his seminal book Antiintellectualism in American Life calls the "national disrespect for mind" (3)-has a long tradition in the United States, and is often conflated with anti-elitism. On the one hand, this is epitomized, as Douthat suggests, by titles such as John LeBoutillier's Harvard Hates America (1978), which claims to expose the elitism, hypocrisy, and essential un-Americanness of Harvard University, and similar fringe publications. On the other hand, it became quite visible in the highly charged rhetoric of the 2012 presidential campaign, during which the Republican candidates, in particular, stood out in their disparagement of 'too much education'. Mitt Romney-himself a graduate of Harvard and Stanford-suggested that Barack Obama had lost touch with the American people because he had "spent too much time at Harvard, perhaps" (quoted in Shahid), while Rick Santorum called Obama a "snob" for advocating for universal college education, cautioning his audience against the inevitable liberal indoctrination awaiting everyone who would dare to venture into the groves of academe (quoted in Somnez). As these examples illustrate, anti-elitist and anti-intellectual sentiment remains alive and well at the same time that the Ivy League and its peers constitute something of a public obsession.

Parallel to this dismissive paradigm of conceptualizing higher education, however, a decidedly more positive attitude emerged. From the early days of the Republic onward, education was thought of as an important engine of social mobility, a vehicle to be used by men and, later, women to advance their position in society. The 'education-as-equalizer'-paradigm, as one might call it, found its perhaps most famous expression in Horace Mann's 1848 report as Commissioner of Education for the state of Massachusetts, in which he argued elegantly for the importance of education in democratic societies: "Education, then, beyond all other devices of human origin, is the great equalizer 
of the conditions of men - the balance-wheel of the social machinery" (quoted in Stabler 70). This notion reflects not only the fundamental American value of equality of opportunity, but also the optimistic belief that education, more than any other social mechanism or institution, would provide the means to realize this goal.

As Lemann points out, however, the "rhetoric of opportunity" (51) had until the mid-twentieth century largely been used to advance "free public schools, paid for by taxpayers' money, open to all [...]-not to argue for selective private institutions for higher learning" (81). Only in the 1950s, in the context of the Sputnik crisis, did efforts to increase access to elite higher education gain momentum. Many of the leading figures in mid-century higher education were deeply elitist, despite their commitments to the development of mass testing and the strategic recruitment of qualified candidates from non-traditional (that is, poor) backgrounds. James Bryant Conant, for instance, Harvard president and immensely influential in the process of introducing the SAT, wanted to support primarily a small number of talented (male, white) students. Conant and his peers saw themselves firmly within the Jeffersonian tradition. Thomas Jefferson laid out his views on education in no uncertain terms in Notes on the State of Virginia (1785): "By this means twenty of the best geniuses will be raked from the rubbish annually, and be instructed, at the public expence, so far as the grammar schools go" (272).

These examples demonstrate the American ambivalence toward the social and cultural value of higher education. Given this ambivalence, it is perhaps no coincidence that education is conspicuously absent from the constitution, which, along with the Bill of Rights, is entirely silent on the issue, relegating it to state and local authorities. Thus, while Americans have a constitutional right to the pursuit of happiness, free speech, and equality before the law, they do not, as of yet, have a constitutional right to education. ${ }^{3}$ Partly as a result of this, the American educational system is extremely heterogeneous in terms of quality, accessibility, and purpose. It is also strongly hierarchical, with stratification occurring not only along the lines of public and private institutions, but also with regard to school districts and neighborhood demographics. There is a saying that if the United States has the five best universities in the world, it also has the five hundred worst, and this indicates the stark discrepancies in terms of the quality of teaching and research between stitution Guarantee the Right to Education?" (The Atlantic, October 2013). 
a select few elite colleges and universities and the many non-elite institutions that cater to the overwhelming majority of students in the US.

The fantasies, desires, and expectations attached to the elite educational space, which I want to address briefly in the following paragraphs, might not necessarily be categorically different from those directed toward non-elite institutions, but they often command more public attention. The discourse of elite education readily offers a number of competing visions of what the function of the elite campus might or ought to be, ranging from the utilitarian and scientific on one end of the spectrum to the humanistic and quasi-religious on the other.

Most commentators agree that the elite educational space should foster the production and transmission of knowledge. There is less agreement, predictably, about the nature of that knowledge, and still less about any attendant or additional functions elite institutions might fulfill. In what is one of the earliest accounts of the purpose of a college education, a short tract titled "New England's First Fruits" (1643), Harvard University formulated its own mission as one central to the success of the Puritan settlement. After settling in New England, the authors explain, "one of the next things we longed for and looked after was to advance learning and perpetuate it to posterity; dreading to leave an illiterate ministry to the churches, when our present ministers shall lie in the dust" ("New England's First Fruits" 568). Harvard's first administrators thus acted out of a professed sense of religious responsibility toward posterity that was informed by a mixture of idealism and utilitarianism. The idealism finds emblematic expression in the life and work of Charles William Eliot, Harvard's longest-running president (1869-1909) and an eminent figure in the history of higher education. Eliot advocated a fervent scientific purism and demanded that "the enthusiastic study of subjects for the love of them without any ulterior objects, the love of learning and research for their own sake, should be the dominant ideas" guiding higher education (214). The utilitarianism, by contrast, is articulated in William A Henry III's In Defense of Elitism (1994), in which he argues that "[s]chools prepare the next entrants into the work force, and the skills and attitudes those pupils absorb will determine the fate of American industry's attempts to compete in a global marketplace" (35). The utilitarian model appears to have gained currency in recent years, as Money Magazine just published a new and alternative ranking of top universities, promising neither academic enlightenment nor personal growth, but a strictly economic cost-benefits analysis: "Using unique measures of educational quality, affordability, and career outcomes, Money's new value rankings 
will help you and your child find the right school at the right price" ("Best Colleges"). While Henry III still stressed the societal function of elite colleges and universities - to strengthen the economy and the nation's global competitive edge-Money Magazine's economically utilitarian vision is geared toward individual gain exclusively. Education, in this scenario, is merely a means to an end, the end being a successful career with adequate monetary compensation.

In addition to the utilitarian and idealistic approaches, which conceptualize education primarily as knowledge transfer and management, a decidedly different vision emerged. Daniel Coit Gilman, president of America's first research university, Johns Hopkins, argued that the university could never be "merely a place for the advancement of knowledge or the acquisition of learning; it will always be a place for the development of character" (quoted in Veysey 161). This holistic paradigm of understanding higher education would prove to be among the most pervasive, informing not only the ways in which the elite educational space was framed discursively, but also playing a crucial role in the politics of admission and exclusion, where 'character' became the central category in the early decades of the twentieth century (Karabel 4). Delbanco, too, emphasizes this function when he writes about the core function of elite educational institutions: A "college should be a place where young people find help for navigating the territory between adolescence and adulthood. It should provide guidance, but not coercion, for students trying to cross that treacherous terrain on their way to self-knowledge" (2012:3). The use of such phrases as 'self-knowledge' demonstrates the extent to which this conception of higher education is indebted to much older, humanistic understandings of the role of educational institutions for individual and social development alike.

In certain contexts, the holistic paradigm of education turns into a spiritual, almost therapeutic vision of the powers of the elite educational space. Consider how Douthat recounts his expectations upon first arriving at Harvard: "Like most newly minted Harvardians, I envisioned college as a magical place, a paradise where the difficulties of my teenage years would be sloughed off and quickly forgotten" (5). To him, the university consequently becomes "a beacon of hope" to his "semi-alienated teenage mind" (7) and, predictably, fails to deliver. A distinctly humanistic twist is added to the holistic vision in the account of Anthony T. Kronman's Education's End: Why Our Colleges and Universities Have Given Up On the Meaning of Life (2007), in which the Yale professor shares his musings on the current state of (elite) education-strayed from its 
rightful path due to an unlucky blend of political correctness, identity politics, and an excessive emphasis on the research ideal. In Kronman's view, education transcends even the therapeutic and appropriates a quasi-religious function in our secular age: Because "the meaning of life is a subject that can be studied in school" (5), the elite educational space should be "a forum for the exploration of life's mystery and meaning through the careful but critical reading of the great works of literary and philosophical imagination that we have inherited from the past" (6).

Last but not least, it has to be pointed out that the conceptualizations of higher education introduced above are overwhelmingly concerned with the individual and the potential merits of his or her collegiate experience. But colleges and universities are first and foremost social institutions, and thus presumably have a collective social function to fulfill as well. The question of the precise nature of this function is at the heart of another strand of critical writing about education that I have already alluded to in the introduction of this book, namely the emerging field of critical university studies. Bill Readings, one of the first to explore these issues in his seminal work The University in Ruins (1996), traces the development of the university as it is in the process of "becoming a different kind of institution, one that is no longer linked to the destiny of the nation-state by virtue of its role as producer, protector, and inculcator of an ideal of national culture" (3).

As this brief survey has demonstrated, there is a range of demands, hopes, and expectations associated with the college in general, and the elite college in particular. Due to a peculiar blend of different functions, the elite educational space raises a more diverse set of expectations than the non-elite. Most elite college still favor a strong emphasis on liberal arts; they furthermore enjoy a reputation of being extremely lucrative in terms of the financial return on the investment; they have a proven track record of producing public leaders (the White House, for instance, has been occupied by graduates of Harvard, Yale, and Princeton for almost half of the twentieth century, cf. Karabel 3) and at the same time are renowned for their excellence in research and scholarship. Because of this eclecticism of functions, the question remains contested as to what 'education' in the elite educational space might or ought to mean. Whom does the elite institution have to answer to? Is it the individual student, the star faculty, the alumni, the local community, society at large, the nation, or posterity? Or does it first and foremost have to answer to itself, as an institution whose primary goal is survival in a highly competitive market environment? Which cultural, political, and educational functions does it ful- 
fill, intentionally and unintentionally? It is part of this study's aim to excavate different positions on these issues, to put them into conversation with one another, and to interrogate their broader socio-cultural implications.

\section{Changes and Continuities: Elite Campuses Then and Now}

In the course of the twentieth century, the elite educational space has been subject to radical and lasting change. In the early twentieth century, elite campuses were strongholds of WASP privilege-places where wealthy families from Boston to Philadelphia sent their children to be groomed among their own kind. This is exemplified, for instance, in the works of Owen Johnson, who chronicles the educational career of his protagonist Dink Stover in a number of novels. Arriving first at his prep school and then, later, at college, Stover encounters a historically specific social environment characterized by homogeneity of race, gender, and class: His classmates at Lawrenceville and Yale-as on early twentieth-century elite campuses across the Northeast-are overwhelmingly white, male, and upper-class. On fictional and non-fictional campuses alike, life reflected the security of privilege, as Karabel points out: "[T] he academic side of the college experience ranked a distant third behind club life and campus activities" (17). By and large, students at elite institutions were far more interested in football and final clubs than in intellectual endeavors of any kind, and, in the words of Harvard Dean Henry A. Yeomans "the group which set the undergraduate standard of idleness were the rich and socially ambitious" (quoted in Karabel 21).

In many ways, there seems to be little resemblance between Stover's Yale and the twenty-first-century image of the elite campuses as vibrant hubs of diversity, originality, and intellectual ambition. Indeed, to the protagonists of more recent elite campus narratives-and their non-fictional counterparts-Stover's campus would be virtually unrecognizable. Among the most visible changes is perhaps the presence of women, who were excluded from Harvard, Yale, Princeton and similar schools for the first half of the twentieth century, but now constitute roughly fifty percent of the student bodies at these institutions. This development is reflected in the proliferation of female protagonists in contemporary elite campus narratives; the stories of Dink Stover, Amory Blaine, and Holden Caulfield are complemented and complicated by those of Lee Fiora, Rory Gilmore, and Charlotte Simmons.

Another important change is the increasing number of students with minority backgrounds. Harvard Dean of Admissions and Financial Aid, William 
R. Fitzsimmons, confidently proclaims that "Harvard is much more diverse than it was even a few years ago and we continue to bolster our efforts to make Harvard even more diverse in the years ahead" (quoted in Conway and Watron). Indeed, some commentators seem inclined to see the elite campus as a 'post-racial' space. But admissions statistics alone do not create a 'postracial' campus. This is illustrated quite poignantly by initiatives such as $I$, too, am Harvard, a photo campaign making visible and explicit the everyday racism still permeating the institution. With this campaign, students of color on the one hand voice their existence: "We are here. This place is ours. We, too, are Harvard" (I, too, am Harvard; emphasis in the original). On the other hand, the blog allows students of color to address the many different ways in which they are still confronted with racist attitudes, comments, and behaviors on a daily basis. I, too, am Harvard - along with its many spin-offs at other institutions-remind the administration and the other students that merely opening the gates to previously excluded groups is not sufficient. The change needed has to be much more substantial: Continued dynamics of discrimination and oppression have to be addressed openly and honestly; infrastructures of support for students of color have to be implemented or expanded; faculty hiring politics have to be scrutinized and adapted; the institutions' history and heritage has to be re-evaluated-in short, room has to be made for intervention and change that might be uncomfortable to those in power.

In one crucial way, however, the elite educational space has remained fairly consistent: Most campuses are still strikingly homogeneous with regard to their students' socio-economic background. Then and now, the majority of students at elite institutions come from the upper strata of the income distribution, need-blind admissions notwithstanding. The socio-economic composition of Harvard's student body, for instance, is such that the school's 'middle income' families are defined as earning between $\$ 110,000$ and $\$ 200,000$ (Delbanco 2007)-a telling fact when one takes into consideration that the median family income in the United States, according to the US Census Bureau, ranges around \$51,000 ("Household Income: 2012"). The socio-political implications of this stark discrepancy are at the heart of recent debates about introducing class-based affirmative action programs. ${ }^{4}$ 
In attempting to make sense of the changes and continuities characterizing the elite campus it is useful to have a closer look at its single most stable quality. The elite educational space is, by definition, an exclusive and exclusionary space. Though elite institutions have not always been 'selective' in the contemporary sense-referring to low admissions rates and high yields-they have always engaged in practices of exclusion. The elite educational space is not only defined by whom it admits - the wealthy, the brilliant, the few-but also by whom it keeps out. In the first half of the twentieth century, this meant not only people of color and women but also Jewish students. After their numbers had risen steadily during the 1910s, Harvard, Yale, and Princeton introduced quotas-between two percent at Princeton and fifteen percent at Harvard-in order to combat what contemporaries called the "Hebrew invasion" (Karabel 119). Incidentally, elite colleges also introduced quotas limiting the numbers of "aspiring scholars and intellectuals" (Karabel 292) in an attempt to remain socially and culturally attractive to their upper-class clientele. Harvard Dean Wilbur Bender, for instance, cautioned against the proliferation of "pansies," "decadent esthetes," and "precious sophisticates" lest it discourage "the normal American boy" (or his affluent parents) from applying (quoted in Karabel 252). Candidates whose strengths were deemed primarily intellectual were subsequently limited to about ten percent of each entering class. In a similar vein, Harvard introduced the 'happy-bottom-quarter'-policy, which granted admissions officers a lot of flexibility in deciding on whom to admit and why (Karabel 291-93). With admission rates well under ten percent, today's elite campuses are highly exclusive spaces as well. The official reasoning behind the practices of admission and exclusion has changed, however-as has their discursive framing. At the heart of policy decisions and the debates that surround them is the concept of merit, which I introduce in the last section of this chapter.

\section{The Study of Elites and Education}

The systematic critical interrogation of the American upper class begins with Theory of the Leisure Class: An Economic Study of Institutions (1899), in which economist and sociologist Thorstein Veblen offers the first comprehensive analysis of the American elite and argues that contemporary stratification

Higginbotham's "Race-based Affirmative Action Is Still Needed," or Angel L. Harris's "As an Alternative to Race, Wealth is Best." 
and practices of consumption can be traced back to tribal societies. Introducing the phrase 'conspicuous consumption' into the American socio-cultural vocabulary, Veblen's study is still considered one of the landmarks of the field. Likewise milestones of American elite theory, C. Wright Mills's The Power Elite (1956) and E. Digby Baltzell's The Protestant Establishment (1964) portray the distribution of power in the United States before the civil rights movement, when the elite was still composed of a fairly homogenous, firmly WASPdominated upper-class establishment. Mills argues that the men leading the large political, military, and economic organizations form a centralized and coherent national power elite that determines the development of society. All other sectors-religion, education, the media-are subordinate to this monolithic elite. Baltzell's Protestant Establishment chronicles the development and lifestyle of the White Anglo-Saxon Protestant (WASP) community, which for the better part of the twentieth century enjoyed control of all the major positions of power in the United States. Baltzell emphasizes its increasingly caste-like nature and the exclusionary practices which, if unchecked, would ultimately lead to the degeneration of the establishment. While many of the observations made by Mills and Baltzell are somewhat outdated in the twenty-first century, their shared attention to the importance on social background and schooling remains important and timely until today.

Following this tradition in contemporary sociology are Thomas Dye and G. William Domhoff, whose studies on the structure and distribution of power in America are updated frequently to include the most recent trends and developments. One of the leading publications in the field,Domhoff's Who Rules America? (2013) is in its seventh edition. Detailed information about his research on the operations of powerin the United States is available also on the related website, whichoffers a concise overview of the issues and questions relevant to thecritical study of power in America. Unlike Mills, who saw atriumvirate of political, business, and military elites at the top of theAmerican society, Domhoff argues that it is the leaders of thecorporate community-the managers of banks, corporations, andagri-businesses-that rule America.

An extensive reader edited by John Scott (The Sociology of Elites Volume I-III, 1990) furthermore provides access to many standard texts in elite theory and offers a useful overview of the various subfields. Elite studies comprises conceptual and methodological issues, political elites, corporate elites, economic elites, critical and comparative perspectives, interest groups, and networking structures. Other comprehensive accounts of the function and composition of the elite in the United States and elsewhere include Tom Bottomore's Élites 
and Society (1993), Eric Carlton's The Few and the Many: A Typology of Elites (1996), Michael Hartmann's Elitesoziologie: Eine Einführung (2004; The Sociology of Elites), Masamichi Sasaki's Elites: New Comparative Perspectives (2008), and Jean-Pascal Daloz's The Sociology of Elite Distinction: From Theoretical to Comparative Perspectives (2010).

In addition to these broad and comprehensive studies of elite influence, there is an increasing amount of research focuses on specific aspects of elite life and culture, investigating the institutional structures, behavioral patterns, and psychological dispositions characterizing the upper strata of society. Offering a plethora of interdisciplinary research opportunities, elite cultures have furthermore been examined not only by sociologists but also by anthropologists, geographers, historians, linguists, psychologists, and gender studies scholars. Some examples of recent research on specific practices, patterns, and institutions include anthropologist Setha Low's Behind the Gates: Life, Security, and the Pursuit of Happiness in Fortress America (2003), in which she examines gated communities and the reasons for joining them, or sociologist Diana Kendall's Members Only: Elite Clubs and the Process of Exclusion (2008), which focuses on exclusive private clubs and their functions with regard to business, networking, and the reproduction of privilege. A member of the social elite himself, Nelson W. Aldrich, Jr. explores the values, attitudes, and myths associated with inherited wealth as opposed to the marketplace mentality of self-made men and the nouveau riche in Old Money: The Mythology of Wealth in America (1996). Sociologist Betty Farrell likewise follows a historical trajectory. Her 1993 book Elite Families: Class and Power in Nineteenth-Century Boston concentrates on the role of elite Boston Brahmin families and the ways in which they shaped and influenced the social and political climate of their time. Mike Donaldson and Scott Poynting, in turn, focus on the contemporary period and explore the private and professional lives of the 'masters of the universe' in their study Ruling Class Men: Money, Sex, Power (2007). Psychologist Madeline Levine, on the other hand, highlights the potential and actual disadvantages of belonging to the elite community in The Price of Privilege: How Parental Pressure and Material Advantage Are Creating a Generation of Disconnected and Unhappy Kids (2008). These publications indicate a lively and growing body of sociological research and their various research emphases provide a road map, of sorts, for cultural studies scholarship. Many of the practices, institutions, and cultural trajectories interrogated in these books operate through a diverse array of cultural channels as well, after all, and derive some of their legitimacy and socio-cultural power through these channels. 
During the past few decades, two approaches to conceptualizing eliteness have dominated the discourse of elite distinction; one can be described as moral/normative, and the other as functional/sociological (Keller 5). The moral/normative approach dominates popular parlance and can be found, for instance, in German encyclopedias such as Brockhaus or Meyer, which define the elite as a social group characterized by above-average skills, abilities, achievements, and societal value (Hartmann 2004: 8). This definition derives from a normative view of the qualities the elite ought to have in order to fulfill its presumed societal function of providing leadership and guidance in a socially responsible fashion. The functional/sociological approach underlies most scholarship in the field of elite studies. Here, the term is defined as referring to "a small number of actors who are situated atop key social structures and exercise significant influence over social and political change" (Markowitz). Even more succinctly, the functional approach posits elites as "[s]mall but powerful minorities with a disproportionate influence in human affairs" (Reid). This definition derives not from alleged qualifications of these minorities but from the actual distribution of power. As Keller points out, the first approach "accounts for the existence of elite groups in terms of the superiority of given individuals, the [second], in terms of the social function of a class or group. The moral approach easily degenerates into mysticism, the functional approach, into tautology" (5). Khan adds to the sociological definition the importance of the "vastly disproportionate control over or access to a resource" (2012:362) and emphasizes the contingency of what counts as a valuable and transferable resource at any given point in time. To study the elite, according to Khan, is to study the distribution and flow of different kinds of resources or capital (ibid.).

A major conceptual distinction in contemporary elite theory is that between 'elitist' and 'pluralist' schools of thought. The elitist school argues that there exists in the United States (or any comparable nation) a single, unified, and internally coherent power elite that determines all kinds of social, political, and economic developments. The pluralist school, by contrast, assumes the existence of a variety of relatively autonomous sub-elites across a range of key sectors, for instance politics, economics, religion, or the media. In a democratic context, the pluralist approach offers a somewhat more reassuring explanation for the issues of inequality and elite influence, since it at least implies a system of checks and balances governing the distribution of power-each sub-elite has a limited sphere of influence and its survival depends on cooperation with the other sub-elites. In order to conquer the 
term's imprecision and broad semantic reach, elite theory furthermore distinguishes between elites that are influential solely in their specific contexts (top poker players, athletes, and the like) and those whose power is relevant to society as a whole. Keller calls the latter "strategic elites" (23). This distinction is echoed in Karabel's definition, who limits his understanding of the elite to the "individuals who occupy the leading positions in major organizations in the economy, the polity, and the culture" (560 n.4).

My own understanding of elite rule aligns most closely with that of political scientist Thomas Dye, who walks a middle ground, of sorts, in his hugely influential book series Who's Running America? Dye identifies more than 7,300 leadership positions across ten key sectors of American society, and explains the power held by the individuals who inhabit them as follows:

Individuals in these positions control more than one-half of the nation's industrial and financial assets, over half of the assets of private foundations and two-thirds of the assets of private universities; they control the television networks, influential newspapers and media empires; they control the most prestigious civic and cultural organizations; they direct the activities of the executive, legislative and judicial branches of the national government. (139)

What is particularly interesting about Dye's conceptualization is the notion of 'interlocking directorates', meaning that some individuals hold more than one of these leadership positions. In fact, more than twenty percent of the roughly 7,300 positions are held by what he calls 'interlockers'. Dye's conception thus introduces a compelling dialogue between pluralist and elitist approaches: While power is spread across a range of sectors, there are numerous connections within each as well as across sectors. Dye furthermore points to the similar socialization shared by many of those who inhabit leadership positions by virtue of their class background and education.

The sphere of education is one of the most widely researched subfields in elite studies. A whole body of research focuses on the admissions policies of private schools and universities and thus emphasizes the ways in which the elite orchestrates its own reproduction, always forced to negotiate between its own class interests on the one hand and the pressures of broader social developments on the other. In his groundbreaking study The Chosen: The Hidden History of Admission and Exclusion at Harvard, Yale, and Princeton (2005), Jerome Karabel portrays how the elite gatekeepers at the Big Three continuously reformulated their admissions policies and redefined the term 'merit' in order 
to control the racial, ethnic, and social composition of each entering class. New York Times education reporter Jacques Steinberg studied the processing of applications and recruitment of students at Wesleyan University, drawing a highly ambivalent picture of the college's attempts at ensuring diversity as well as financial solvency. On the one hand, Steinberg portrays the admissions officers as human and caring actors in a process that is all too often very painful for the applicants, but on the other hand he also points to the discriminatory treatment of certain groups of applicants, for instance Asian American students, who are held to higher standards than others. Interestingly, Steingberg's book also points to the disappointment the admissions officer feels when a candidate he has tried to recruit chooses a different university-this side of the process is rarely addressed in the discourse (The Gatekeepers: Inside the Admissions Process of a Premier College, 2002). Similarly, Mitchell L. Stevens spent one and a half years working in the admissions office of an elite New England college, describing in detail how the admissions officers navigate the at times conflicting interests of the college administration, faculty, and the public in the admissions process. This book will be discussed in greater detail in the second chapter of this study (Creating a Class: College Admissions and the Education of Elites, 2009).

In addition to these studies of the dynamics of admission and exclusion, another group of books focuses on the processes of elite identity formation and group cohesion that occur at and through elite educational institutions. Peter W. Cookson, Jr. and Caroline Hodges Persell were the first to conduct an in-depth examination of how young members of the elite are socialized and trained for the positions of power they are destined to inhabit. Relying on an array of sources, including questionnaires and interviews with students and alumni, Cookson and Persell describe the complex socialization process students undergo at elite prep schools, a process that is defined by a highly competitive environment with little privacy, and an intense pressure to excel. Upon its completion, this process creates a sense of legitimacy in the graduates of these schools, or, as one reviewer puts it, "[i]n one stroke, then, the prep school experience facilitates class cohesion and class legitimation" (Karen 479). Another way in which elite prep schools prepare their students for powerful positions is the college application process, in which they have clear advantages through competent guidance counselors, social networks, and strong ties between the schools and elite colleges (Preparing for Power: America's Elite Boarding Schools, 1985). Alan H. Levy's study Elite Education and the Private School: Excellence and Arrogance at Phillips Exeter Academy 
(1990) offers some valuable insight into the educational and cultural microcosm of boarding schools, but has been criticized for being unnecessarily harsh and polemical. Similar sociological investigations of the role of boarding schools in the formation of elite identities have been conducted recently by Rubén Gaztambide-Fernández (The Best of the Best: Becoming Elite at an American Boarding School, 2009) and Columbia sociologist Shamus Rahman Khan (Privilege: The Making of an Adolescent Elite at St. Paul's School, 2011). GaztambideFernández develops an intricate model that captures the different processes that let students develop elite subjectivities in the course of their time at the school. He calls this model "the five E's of elite schooling" (6), and describes it as follows:

Students at the Weston School are carefully selected from hundred of applicants through a complex admissions process that involves standardized tests, essays, recommendations, and often interviews. While the explicit purpose of the admissions process is to choose who will be allowed inside, the implicit purpose is to exclude and to provide a rational for such exclusions. Once admitted and enrolled, students engage a plethora of learning opportunities in a wide range of academic, athletic, and artistic disciplines [...]. As students develop their talents and demonstrate their excellence, they confirm their entitlement to the privilege of a Weston education. At the end of their Weston careers, students envision themselves in other equally elite spaces, pursuing challenging careers and assuming leadership roles. (6)

Gaztambide-Fernández's account thus mirrors that of Cookson and Persell in that he stresses the dual nature of the elite boarding school socialization: On the one hand, the changes it produces in the way students think about themselves and their privilege, and on the other hand the support the institutions grants them in creating a portfolio of skills and accomplishments needed to get into an elite college.

In Perfectly Prep: Gender Extremes at a New England Prep School, (2008), anthropologist Sarah A. Chase studies the construction and performance of gender at a small elite boarding school. She investigates the different kinds of pressures felt by girls and boys and discusses the influence of ethnic difference and socio-economic status on how gender is experienced and performed. While all students are "caught in the crossfire" of conflicting values and expectations, Chase argues that girls fair worse than boys: "I learned that boys thought that 'it would suck' to be a girl and that one third of the girls would be male if given the chance" (3). These dynamics are particularly problematic, ac- 
cording to Chase, since many of the students thus socialized go on to inhabit positions of power and influence in American society.

As these studies demonstrate, there is now, and has been throughout the twentieth century, a peculiar connection between the elite and the educational system in the United States; the production of power and the production of knowledge go hand in hand. An uneasy form of mutual dependence joins two sets of social actors whose interests, to some degree, overlap, but at the same time might contradict each other: the reproduction of privilege and power on the one hand, and the education of responsible future citizens and leaders on the other. At the same time, elite colleges and universities of course also offer educational services in the narrower sense of the term and have to navigate their faculty's research and teaching interests as well as the educational goals of their students. To further complicate matters, the negotiation of these interests takes place in a socio-cultural context that likewise weighs in and, occasionally, forces a response from the parties involved: Political movements, such as the Civil Rights movement or feminism, have had a lasting effect on the elite educational landscape, and, by extension, on the elite that frequents it. Scholars agree that institutionalized education plays a pivotal role in the culture and politics of the elite. As the primary space in which elite identities are forged and in-group cohesion is created, the campus provides ample room for the distribution of social and cultural capital and is thus crucial to the reproduction of the elite group. Historically, colleges and especially prep schools have furthermore facilitated the recruitment of new members and the merging of old names with new money (Levine 1980). Thus, as Mills points out, "[t]he school—rather than the upper-class family-is the most important agency for transmitting the traditions of the upper social classes, and regulating the admission of new wealth and talent." He therefore concludes that education "is the characterizing point in the upper-class experience" (64-5). Though much has changed in the educational field since the 1950s, contemporary sociologists largely agree with Mills's assessment of the importance of education. Michael Hartmann, for instance, discusses the key role of elite degrees in gaining access to top positions in politics, business, administration, and the law (2007: 61). Khan points to one of the most important functions of elite institutions, namely that of creating legitimacy, arguing that elite institutions are "engines of inequality" because they often help "to convert birthright into credentials and thereby obscure[e] some of the ways elites are reproduced" (2012: 372). 
At the same time, as the phrase 'When Harvard speaks, the country listens' (quoted in Kridel 161) suggests, elite educational institutions have always played an important role in the culture and politics of American higher education in general. Ernest Earnest elaborates: "To an amazing degree the pattern set by Harvard, Yale and Princeton after 1880 became that of colleges all over the country. The clubs, the social organizations, the athletes-even the clothes and the slang-of the 'big three' were copied by college youth throughout the nation" (204). Elite institutions themselves have consciously adopted the role of leaders and role models, as this statement by Kingman Brewster, Jr., Yale President from 1963 to 1977, suggests:

I think it's fair to say, without being too officious or self-congratulatory, and I hope not smug, that it has been and is the ancient privilege of endowed free universities of this country, particularly in the northeast, ... [to be] the yardstick, not only for the independent rivals in the Ivy League and elsewhere, but the yardstick for the fast growing and very rapidly improving state institutions in the west and far west. (quoted in Soares 6)

It is not surprising, then, that the authors of recent books on higher education in the United States choose to focus on elite institutions. Delbanco points out that elite colleges "have peculiar salience for understanding the past [and] wield considerable influence in the present debate over which educational principles should be sustained, adapted, or abandoned in the future" (2012: 6) and thus provide the best lens through which to examine the cultural meanings of college in America. Menand explains his focus on "a very thin slice of the whole" in similar terms and claims that "historically, the elites have had the resources to innovate and the visibility to set standards for the system as a whole" (2010: 18).

This peculiar relationship of mutual dependence thus manifests itself in the highly disproportionate amount of attention elite institutions command in American public discourse. As Derek Bok explains, "higher education in the United States has grown to become a vast enterprise comprising some 4,500 different colleges and universities, more than 20 million students, 1.4 million faculty members, and aggregate annual expenditures exceeding 400 billion dollars" (9). Given the range, diversity, and sheer numbers of institutions-research universities, professional schools, technical colleges, liberal arts colleges, community colleges, among others - those colleges that deserve the moniker 'elite' by virtue of their high selectivity constitute but an extremely small piece of the higher education pie. Most scholars working on elite edu- 
cation use Barron's Profiles of American Colleges, which identifies roughly 200 to 250 colleges as 'very competitive' or 'most competitive', as a guide (cf. Leonhardt 2013); this means that between 4.5 and 5.5 percent of colleges are classified as 'elite'. A similar case can be made for the influence wielded by high schools. Douthat writes:

There are 31,700 high schools, public and private, nationwide, but only 930-roughly 3 percent—could claim more than four students in their 19982001 graduating classes who matriculated at Yale, Harvard, or Princeton. And Worth's top hundred sent a total of 3,452 kids to the big three during that time, meaning that roughly 22 percent of the 'Yarvton' student bodies emerged from fewer than 0.3 percent of America's high schools. (50)

The media coverage, the number of fictional accounts, and the general visibility and discursive leverage these highly selective institutions hold seem to suggest that every other American teen attends an elite school, and they create an image of the student at an elite institution as 'the' generic college student, which makes actual facts-for instance that "more than 40 percent of all undergraduates in this country are over the age of twenty-four, and close to 40 percent study part-time" (Bok 16)-seem surprising. Thus, there is an obvious and important imbalance whose cultural and socio-political implications will be discussed in a later section of this study.

\section{4. 'Excellence and Equity': Merit as the Price of Admission}

In addition to and continuously in dialogue with eliteness, merit is the second central trope around which the epistemology of elite education revolves. For the past few decades, it has been at the heart of most debates surrounding the elite educational space and its socio-cultural and political implications; Karabel even proposes that the entire "history of admissions at the Big Three has [...] been, fundamentally, a history of recurrent struggles over the meaning of 'merit"' (5). In this section, I share some general observations on the role of merit in the context of elite education, and discuss the history and current discursive role of the notion of a 'meritocracy'. 